\title{
The Nexus Between Philosophy and Science: The Import of Philosophy of Science to Science and Philosophy Itself
}

\author{
Jemal Hussein Abdulle \\ Department of Philosophy, Oda Bultum University, Chiro, Ethiopia \\ Email address: \\ Jemalhussein7@gmail.com \\ To cite this article: \\ Jemal Hussein Abdulle. The Nexus Between Philosophy and Science: The Import of Philosophy of Science to Science and Philosophy Itself. \\ International Journal of Philosophy. Vol. 7, No. 3, 2019, pp. 107-112. doi: 10.11648/j.ijp.20190703.11
}

Received: May 30, 2019; Accepted: July 25, 2019; Published: August 28, 2019

\begin{abstract}
This short paper explores the overall relation between philosophy of science and science such as the influence of one over the other, the major aim of philosophy of science and the contribution of philosophy of science to philosophy itself. A lot of peoples confused of the very meaning and contribution of philosophy in general and philosophy of science in particular so as they believe that as if philosophy is done in the vacuum without basing on any practical evidence in human life. So, the central argument of this paper is to show how philosophy of science, philosophy in general, able to do with science or empirical concern and aware those peoples who have misconception about it. I try to show how philosophy and science are interdependent on each other. Both disciples share common denominators in many ways as they try to understand and influence each other in different epochs of human life. But through the passage of time, people start to doubt as if philosophy has less contribution in human life and only concentrate on playing with words rather than giving attention to tackle practical human problems comparing with sciences. I suggest that philosophy has indirect contribution for human life as it tries to be foundational for scientific theories and practices.
\end{abstract}

Keywords: Philosophy of Science, Science, Philosophy, Kant's Copernican Revolution, Shift to the Subject, Logical Positivism

\section{Introduction}

There are a lot of confusion regarding the relation between philosophy of science and science. This is what initiates me to write this article. I shared this confusion with so many people in my experience of studying philosophy. When I was attending philosophy of science class at Addis Ababa University post graduate program, I asked my instructor that whether there is substantial or practical influence of one another between the two disciplines. So my instructor Dr Setergew Kenew inspired me to write short term paper on this area to come out of the confusion. This was a time that I started to navigate through my confusion. The confusion is whether philosophy of science, philosophy in broader sense, has any place in practical activities of human concern including its influence on scientific issues. But their difference is common, as many believe, science generally speaking concerned with practice whereas that of philosophy is theory. A lot of scholars try to compromise both disciplines from different perspectives including their difference, relation and contribution. Massimo Pigliucci claims that "there is no such thing as philosophy-free science; there is only science whose philosophical baggage is taken on board without examination" [1].

In the history of philosophy and science, someone can find one in the other either directly or indirectly. To proof this statement, I can raise question like: Can science and philosophy develop without the support of one another? Or can science be able to do its activity without the support of philosophy? And can philosophy be free from science? According to Spirkinsome people believe that sciences can independently do its activities without basing on philosophy in the sense that philosophy as something which is groundless and vague theorizing that is done in the vacuum [2]. But spirkin argues that true science should not break its connection with true philosophy. Since there is influence of one over the other in the history of both disciplines; one cannot be free from the other. In other words, the interdependence of two disciplines in which philosophy strive to theorize, supplies universal methodology and 
generalize the practice of science is enable scientist to refer as a foundation of their world-view and thereby, try to develop another scientific research based upon the existing philosophical thought(ibid). Kun Wu also suggests that "the recently developed Philosophy of Information has integrated the unique dualistic ontological properties of information, and scientific rationality can now be seen to include an interactive relationship between science and philosophy" [3]. Of course it's common to indicate the connection between philosophy and science. But there is no extensive works done on the contribution of philosophy of sciences to science and philosophy itself. Therefore, this is what inspired me to write this article. Having provided this clue, I will try to discuss and critically examine thematic points regarding the relation between science and philosophy of science, whether philosophy of science necessarily cater to science or not and the import of philosophy of science to philosophy itself.

In this article the researcher tries to consider relevant documents on the areas and used qualitative research approach to achieve meaningful conclusion. In order to achieve objective of this paper, both primary and secondary datum were utilized. Apparently, different literatures that indicate the correlation between science and philosophy have been employed. Primary sources like discussions with academic philosophers and students of philosophy were employed. Furthermore, various secondary sources like books, articles, and academic literatures that are related to the subject matter were critically and rationally analyzed.

The weakness of this article is that I am philosopher, and most of my examples will be from philosophy. This being part of my professional bias, I will try to show some interaction between philosophy and science even though I lacked deep knowledge and understanding of basic scientific theories and practices. The strength of this article is that in the current world people becoming naïve about philosophy in general and philosophy of science in particular. So that this article can play its part to bring back the credibility of philosophy and uplift import of philosophy for science. In addition, it can update attention of scientists for philosophers.

\section{Discussion}

As I tried to mention in the introductory part of this paper, there is a misunderstanding of many people on the relation between philosophy of science and science. So to solve a problem, let me try to answer different questions concerning the issue under discussion. "How much crossover could there be between science and philosophy of science?" Waugh and Ariew put their relation as follows:

Philosophy and science, as well as their respective histories, are not recognized as distinct genres until relatively late in Western philosophy. Even when they are thought to be distinct genres, neither can be written independently of the other, occasional protestations to the contrary notwithstanding. Philosophy and science were seen as almost one and the same activity for most of Western intellectual history, and the description of the relations between the history of philosophy and the philosophy of science not only forms a very large part of any account of philosophy and its history, but must include discussion of the history of science as well. Still, the terms "philosophy," "history of philosophy," "history of science," and "philosophy of science" are not interchangeable because the networks of associated concepts and practices constituting each activity change over the long history of their relations [4].

This quotation implies that in the long history of mankind both philosophy and science have a common background in the sense that, as commonly believed, there was a time when philosophy has a nick name 'a mother of all sciences.' Basically the relation between philosophy and science are intertwined or interdependence so as in both disciplines there is epistemology, metaphysics and different kinds of theories that are common for both of them even though the way they look at things are different. In other words, Science gave philosophy a way of empirically testing theories and concepts, while philosophy can contribute indirectly to the development of scientific theories that we are using today in a different ways. Furthermore, Philosophy also enables to show what areas science can and cannot test, demarcating the boundary between physical and metaphysical questions and thereby, based on this boundary both disciplines developed their own way of conducting research over the centuries. In line with this, philosophy of science also underlies methodology and foundations of the scientific process that contributes in shaping science in today's world. To show how one influence the other, let me briefly discuss concepts like: logical positivism, Copernicus influence on the Kant's philosophy (Kant's Copernican Revolution), Descartes' philosophy on Quantum theory in physics, Heisenberg's notion of "The role of modern physics in the present development of human thinking" etc.

Logical positivism, as one school of philosophy, has a great influence on a science. It develops criteria for meaningful statements called 'the principle of verification' 2 that enabled them to reject many traditional debates as nonsense, particularly, that concerned with metaphysical issues of philosophy. Its influence goes to many disciplines like physics, linguistics and psychology. For them, the only real knowledge is scientific knowledge by a process of logical analysis that can be reduced to symbolic formulas constructed from atomic facts [5]. In other words, it is an attempt to revolutionize philosophy as antithesis of traditional philosophy. In traditional philosophy, more of the issue of concern is about metaphysical speculation which is out of our experience and very difficult to reach on the agreement for the philosophers. But after the coming of logical positivist, they revolutionized philosophy in a sense that all metaphysical issues are meaningless. They say if the

1 Note that I used the term 'a mother of all science' to refer to what many thinkers used to dub philosophy in ancient times so as through gradual process that different disciples split from it.

2 Logical positivist use the term 'the principle of verification' refers to linguistic analysis of philosophical terms or statements to repel problems of philosophy. 
method of science is used in a philosophy, it is possible to solve the questions or problems of philosophy. In other words, analysis of concept is very important method to solve philosophical issues. Therefore, this shows the relation between philosophy of science and science (ibid). In addition, positivist tradition introduces new methodological issues in the social science research based on data which is objective, neutral etc [6].

The next point is Copernicus influence on Kant's philosophy (Kant's Copernican revolution). Kant is one of the prominent figures in the development of Enlightenment and post-Enlightenment thought. And all the subsequent philosophical thought, in one way or the other, is a development from or reaction to his philosophical foundation and he is respected as a major figure by later philosophers in both analytic and continental traditions. His philosophy was an attempt to save the Enlightenment from "Hume's skepticism" ${ }^{3}$ by fostering the confidence in reason, science and progress of mankind as a means of revealing true knowledge of reality. Kant's solution would involve an attempt to solve the conflict between Rationalism and Empiricism as a great opposite philosophical camp that threat Enlightenment confidence in dividing philosophers into two irreconcilable camps so long as Empiricists advocate all source of knowledge is a posteriori or knowledge can be gained only through experience whereas rationalists believe in opposite or source of our knowledge is prior to any experience [7].

In connection to this, Kant develops the concept "Shift to the subject" " which implies our knowledge goes from mind to things in the world. It has direct relations with Kant's Copernican Revolution that shifted the history of philosophy at a glance. For him the first important point was to realize that the new philosophy, unlike the old one, would always go not from things to ideas, but from ideas to things. For instance, to answer the question: what is a circle? Is it this and that circle, such as, I can imperfectly draw on a piece of paper or on a black board? The answer is not, because the real circle is a definition of a circle and nothing else. The essence or true nature of the circle is that only found in its definition, and only there in our mind. So long as Copernicus brought revolution in astronomy, Kant brought revolution in human thought or philosophy. In other words, as Copernicus challenged assumption in universe, Kant challenged assumption on human thought. Here it implies that Kant has been influenced by Copernicus's concept in a science. In relation to this, Kant suggested that instead of mind having to conform to what can be known, what can be known must conform to the mind. The old paradigm: our thought has to conform to the objects. But, Kant came-up with new

3 'Hume's skepticism' in this context refers to Hume's ambition to influence his contemporary peoples by advocating radical empiricism which awakens Kant from dogmatic slumber to reconcile empiricism and rationalism.

4 I used the term 'shift to the subject' to mean that before Kant's time many peoples believe that our knowledge goes from objects around us to our mind; but after the coming of Kant he changed this notion to the inverse. It means our knowledge goes from mind to objects around us and that is why we call his philosophy shift to the subject. paradigm which says the objects to be known must conform to our mind. In addition, in astronomy the old paradigm implies that the geocentricism or sun revolves around the earth. Whereas, the new paradigm implies 'heliocentric' ${ }^{5}$ or the earth revolves around the sun (ibid).

Furthermore, Hourya Benis Sinaceur tries to show the influence of Kant's work on scientific knowledge. Sinaceur claims that "Critique of Pure Reason still has a legitimate claim to provide us with foundations of science after the scientific and epistemological revolutions of non-Euclidean geometry, relativity theory, and quantum physics [8]."

The other point is contribution of Descartes philosophy in quantum theory in physics. As we know Descartes laid a foundation for philosophical thought through bringing new system in solving major philosophical problems such as how we enable to reach on the level of certainty and mind-body problems. It means that he tries to mathematize philosophy to look for certainty. In other words, his interest is to come-up with philosophical system that starts from logical reasoning and to arrive at some truth that was as certain as mathematical conclusion. In connection with this, Galileo has been influenced by Descartes philosophy and thereby, produced his quantum mechanics theory of motion which has profound influence in physics for a long period of time. So, natural sciences begun to deal with the interplay between nature and ourselves just like Descartes tries to design the relation between our mind and things out there [9].

Having discussed the influence of philosophy on science; let me proceed to indicate the influence of science on philosophy to explicate further how both disciplines determine one another. For instance, Heisenberg's notion of "The role of modern physics in the present development of human thinking", one way or the other, explores the contribution of physics, as one branch of science, in the progress of human thought or philosophy. Heisenberg puts as such: "All that has here been said about international cooperation and exchange of ideas would of course be equally true for any part of modern science; it is by no means confined to atomic physics" indicated under [9]. It implies that the human thinking of different communities across the world has the influence of physics implicitly or explicitly since it becomes the agenda for many people at different level of social groups. In other words, the way peoples were thinking during classical period and the way people think in contemporary time on the same agenda is something different because of great influence of physics on different human thought like politics, economics, philosophy, psychology and other areas of study. For instance, look at what is going on in the contemporary world regarding atomic bombs influence on political situations of different nations in the globe. It means that today politicians make this new weapon a subject of debate in their daily activity both within a given country and across different nations. As a result, nuclear bomb became a source of debate, tension and conflict between

5Note that 'heliocentric' is the idea of Copernicus in astronomy which implies the earth revolves around the sun unlike the old astronomy or Ptolemy and Aristotelian view which advocates the sun revolves around the earth. 
many states in the world that can even affect or influence the thinking of new generations as a result of modern physics that has a great role in the progress of science which enable to conquer the material world. Consequently, philosophy or philosophy of science and science are intertwined because of different reasons that I have discussed so far.

The other point is "does philosophy of science necessarily cater (supplies) to science?" and "what is the import (importance) of philosophy of science to philosophy itself?" The answer for the former question is no, because philosophy of science necessarily foster philosophical knowledge than scientific knowledge. In other words, since philosophy of science is part of philosophy, not a science, it can help science but not necessarily. Just like aesthetics is more of contribution to philosophy not to arts and other related areas. In connection to this, aesthetics can help artists but not necessarily and the same for philosophy of science to science indicated under [6].

To answer for the last question it's important to concentrate on the very meaning and scope of philosophy of science, and epistemology as branches of philosophy. Philosophy of science, as more specific theory of knowledge, reflects on the nature of scientific theories rather than deeply digging with scientific facts one by one. Theory of knowledge or epistemology as a matter of course goes beyond the scope of philosophy of science in the sense that it focuses on the very general philosophical issues such as "what is the ultimate basis of knowledge?" In other words, epistemology which tries to answer question 'what is knowledge?' is broader than philosophy of science which tries to answer particular question 'what is scientific knowledge?' So, in this case as epistemology tries to comeup with further philosophical knowledge, philosophy of science also tries to come-up with further philosophical knowledge from scientific concerns. As a result, it further develops knowledge of philosophy through bringing a new form of data from scientific theories or issues. To proof the above idea Siegel puts as follows:

It is suggested in addition that the philosophy of science itself best seen as a primarily epistemological activity, and consequently that a correction from the excessively historicist conception of recent philosophy of science is in order [10].

Here the intension is to show the extent of philosophy of science's interfering in the scientific activity or concern in the sense that it is not expected to deal with each and every points in scientific procedures. In other words, So long as philosophy of science is targeted to foster epistemological knowledge of philosophy; it has a sort of limitation in doing with all kinds of procedures in scientific methodologies as the scientist do in their daily life rather philosophers can comment general overviews regarding scientific innovations, paradigms and offering general guidance on how scientists have to proceed their work. But philosophy of science mainly fosters epistemology or theory of knowledge for philosophy except analyzing and may be guiding the issues related with science from philosophical points of views. As a result, this shows the bridge between philosophy of science and science, and philosophy of science and philosophy itself.

\section{Critical Remarks}

As I tried to illustrate throughout the forgoing portion of this paper, it's possible to find a certain sort of relation between philosophy of science and science either directly or indirectly in a way that one evolves out of the other and the ending up of philosophy of science is rest mainly in fostering the epistemological parts of philosophy rather than scientific knowledge. As I said earlier, philosophy of science doesn't mean that it has no any contribution to science rather it has a role to play in fostering scientific knowledge but not necessarily. To explicate the first question, their relation also goes to the points where they have common issues to deal with in a way that enable to foster or show mutual understanding in their evolution. Mumford forwarded as follows:

Both science and metaphysics are concerned with the question of what there is and, to that extent; they have the same subject matter. Historically, some of the most significant debates in metaphysics have concerned the nature of universals (properties and relations), substance, causation, laws of nature, modality, identity, time and truth This list is not exhaustive; however, there can be metaphysical issues in all other areas of philosophy. The mind-body problem is metaphysical debate in the philosophy of mind, for instance, and in philosophical logic we may consider the nature and existence of propositions and logical forms, which is toconsider metaphysical issues indicated under [4].

It shows how much philosophy and science have a common background issues to deal with in the long history of mankind. In other words, both of them were dealing with similar issues, say, concepts of "corpuscles or substance, laws of nature, time, etc." as both subject of philosophy or metaphysics and physics even though the ways they look at things may be different from each other. Therefore, these shows how much the discipline under discussion are interlinked from different perspective of human life in the evolution of human beings. Personally I agree with the positive relations between philosophy and science in the sense that they have the habit of cross-cultural understanding even in the contemporary world since one cannot do fully its activity without the support or intervention of the other by any means.

In contrast to the above idea, there are some scholars who rejected the values of philosophy in general. For instance, C. D Broad was English philosopher and he devalues the value of philosophy in many ways. According to Broad, Philosophers spent their time on useless theories which can neither be supported nor refuted by experiment. In connection to this, philosophers discuss, he argues, issues like 'the immortality of the soul', 'the existence of God' and 'the freedom of the will' which no two philosophers can agree since we cannot proof them by experiment. As a result, there is no progress in 
philosophy in such a way that philosophers are still discussing the same questions with that of ancient Greece philosophers were doing thousands of years ago. But in natural science, he believes, one can find a continual steady progress so long as the event or innovation of one age can be accepted by the other and serve as a base for further knowledge of science. But, he argues, it doesn't mean that there is no controversy and debate in science; in fact there is, but unlike philosophers, it is a fruitful controversy that ends in agreement and helps science to achieve its goal or aim. For him philosophy is a mere playing with words or vague that tries to deal with issues beyond human intelligent [11].

But if his idea is so regarding philosophy, how it's possible to categorize this guy under members of philosophers? It seems to me that he is contradicting himself since he rejects the value of philosophy in one hand and thinking of himself as a philosopher on the other hand. In the first place he has to be either non-philosopher in profession or advocator of practical parts of philosophy like pragmatists or positivists which are more of trying to relate philosophy with science or practical issues. Being a pragmatist itself cannot deserve to say philosophy is something useless rather they can criticize some parts of philosophy which mainly focus on more of theoretical concerns like metaphysics. For me his problem goes beyond problem of philosophy since he tries to play with dual identification card at a glance. In other words, he is neither scientist nor philosopher, I believe, rather I place him in the vacuum.

Like CD Broad, in their book entitled The Grand Design (2010) Stephen Hawking and Leonard Mlodinow devalued the value of philosophy by saying that philosophy is dead in the modern world. Hawking and Mlodinow claim that traditionally issues like reality, studies about the universe, and the like were concern of philosophy but in the modern world they are the concern of physics [12].

In contrast with the above views, I argue, since philosophy and science evolve from one another in the sense that at least one has contribution in the evolution and development of the other in many ways. Furthermore, Spirkin also claims;

Besides influencing the development of the specialised fields of knowledge, philosophy itself has been substantially enriched by progress in the concrete sciences. Every major scientific discovery is at the same time a step forward in the development of the philosophical world-view and methodology. Philosophical statements are based on sets of facts studied by the sciences and also on the system of propositions, principles, concepts and laws discovered through the generalization of these facts. The achievements of the specialized sciences are summed up in philosophical statements indicated under [2].

This quotation implies that the history of science tracing back to some hundreds of years ago, there was significant role of human reason in the achievement of scientific discoveries through constructing world-views and different methodologies for science by either scientists or philosophers. For instance, intellectual revolution that produced by Copernicus' heliocentric system that changed the whole conception of the structure of the universe and our conception of man's place in nature. The other example is "Einstein's theory of relativity changed our notion of the relationship between matter, motion, space and time" (ibid). In addition, the works of Marx, Engels and Lenin on the science particularly regarding the laws of development of human society has changed people's view of their place in nature and social context. So this is special achievement of human reason in shaping notion of the universe as well as ourselves.

In contrast to the above idea, some scholars may think that science reached such a level that philosophy is no more important for scientific knowledge. But Spirkin argues, which I am also sympathetic with, the scientist knows in their heart that their creative activity has a close relation with philosophy in a way that without having philosophical knowledge, a given activity will end-up theoretically ineffective. As a result, all theoreticians have to be guided by philosophical thought that inspire people significantly enable them to understand and critically analyze all the principles or systems that considered as a science (ibid). In other words, scientific thought is philosophical to the core and philosophical thought is also scientific so as philosophical training gives the scientist a breath or inspiration to solve different problems of science. Consequently, for him real scientists that have a powerful grasp of theoretical knowledge are never turning their backs on philosophy. In connection to this, he puts the same idea as such "The common ground of a substantial part of the content of science, its facts and laws has always related it to philosophy, particularly in the field of the theory of knowledge, and today this common....inventions" (ibid). Regarding the importance of philosophy, Naffadi Alsayyed reveals "We are in need to restore for philosophy its lost throne and its previous effective role to participate with politicians, scientists and technocrats in drawing the map of the future, for the sake of man as such, his happiness and his good live [13]."As I have tried to discuss earlier, in ancient times every scientist at the same time a philosopher and every philosopher was also a scientist at least to some extent.

In my view, science has a confidence and rich because of it born from rich father that is philosophy. Those who say philosophy does not beg bread is end up in philosophy. But those who say philosophy can make bread would end up in science. When philosophy asks question how do you make or beg bread? Scientist answers through scientific method. But Philosophy is telling science that there is not only one way of making bread rather many ways. In connection with this view, Peter Godfrey-Smith claims another role consistently played by philosophy is what I will call an incubator role. Philosophy is a place where ideas are developed in speculative and broad form, in theory-sketches and schemata, that often then make their way into an empirical form within some science, or into a mathematical form, or some other more focused form [14].

As father gives an advice philosophy afford an advice to science. The more science starts to think deeply regarding nature, the more they are returning back to the very concept of philosophy. In other words, the deeper science think about nature, the closer it gives attention to philosophy (the more it listen philosophy). Moreover, philosophy serves as a fuel for 
science to operate its activity. In line with this, Sebastian de Haro also suggests that "philosophy isuse less for science is not only false; it is also harmful for education, for society, and ultimately for science itself [15]."Generally, relation between philosophy and science is mutual or deep interaction for thousands of years.

\section{Conclusion}

As it had been discussed so far in previous sections of this paper, the relation between philosophy and science is intertwined for a long period of time as I tried to mention the ideas of many thinkers throughout this essay so long as both disciplines were shared a lot of things together from different perspective. But latter on through gradual process they split in to independent disciplines with their own areas of studies and scopes. In other words, philosophy answers fundamental question through postulating theories and critically evaluating issues like matter, causal relation, religion, reality etc. In relation to this, philosophy answers why question whereas science answers what question or concrete concerns of human life. The next point is whether philosophy of science necessarily caters to science or not. It is not necessarily cater to the science as far as philosophy of science aimed to broaden the horizon of epistemology as a branch of philosophy. Furthermore, philosophy has indirect contribution for human life as it tries to be foundational for scientific theories and practices. Lastly, philosophy of science mainly imports significant knowledge to philosophy. But it does not mean that philosophy of science not helps science, of course, it can help it.

\section{References}

[1] Pigliucci, M. 2008 The Borderlands between Science and Philosophy: An Introduction. Stony Brook, New York 11794 USA.
[2] Spirkin, A. 1984 Dialectical materialism. London: Central Books.

[3] Wu, K. 2016 The Interaction and Convergence of the Philosophy and Science of Information.

[4] International Center for the Philosophy of Information, Xi' an JiaoTong University, Xi'an 710048, ChinaPsillos, S. 2008 The Routledge Companionto Philosophy of Science. NewYork: Taylor \& F. e-library.

[5] Lacewing, M. 2011 The project of logical positivism. New York: Routledge, Taylor \& F. group.

[6] Kenaw, Setargew (PhD), (2015) Unpublished Lecture Notes on philosophy of science: Addis Ababa University, Department of Philosophy.

[7] Rouch, E. 2007 playing with Good and Evil: Videogames and moral philosophy. Florida: Atlantic University.

[8] Sinaceur, H. 2018 Scientific Philosophy and Philosophical Science. HAL Id: halshs-01935233 https://halshs.archivesouvertes.fr/halshs-01935233.

[9] Heisenberg, W. 1958. Physics and Philosophy: USA. New York

[10] Seigel, H. 1985 What is the Question Concerning The Rationality of Science? USA: TheUniversity of Chicago Press.

[11] Broad, C. 1927 Scientific Thought: New York. Brace and Company, ink.

[12] Hawking, S. and Mlodinow L. 2010 The Grand Design. Bantam Books: New York.

[13] Alsayyed, N. 2002 The Relation between Philosophy, Science, and Technology. Philosophy and Current Epoch, The Higher Council for Culture, Cairo - Egypt, no. 2, 2002, Pp. 109-129.

[14] Godfrey-Smith, P. 2013 On the Relation Between Philosophy and Science. City University of New York.

[15] Haro, S. 2013Science and Philosophy: A Love-Hate Relationship. Institute for Theoretical Physics and Amsterdam University College, University of Amsterdam PO Box 94160, 1090 GD Amsterdam, The Netherlands. 